\title{
Reusable e-learning development: Case studies, practices and issues of awareness for knowledge-based organisations (Category: Academic/Technical)
}

\author{
Victor Chang \\ Web Development Officer, Department of Physics, \\ University of Cambridge, United Kingdom \\ icvc2@phy.cam.ac.uk
}

\begin{abstract}
Reusable e-learning development (RED) is defined as the cloning, modification and customisation of existing files or source codes for developing another website or another webbased application. RED does not imply just copying and changing existing files or source codes but rather, it provides a practical technique for time-saving, improving efficiency and maximising utility of existing resources for creating another website or another web-based application. RED is particularly useful for a large-scale web development, where there is an extremely high degree of overlapping of information, resources and web designs. Therefore, RED has been widely adopted by many knowledge-based organisations (KBO). In order to investigate the impacts of RED on KBO, various case studies, practices and issues of awareness for $\mathrm{KBO}$ are presented and analysed. This paper particularly focuses on studies and recommended practices from the University of Cambridge. Results from these case studies reveal a number of outcomes as described below.
\end{abstract}

Firstly, RED has increased work efficiency by decreasing the quality project completion period, on average by 2-3 times less than the estimated period. This is particularly true for the Department of Physics at the University of Cambridge (DPUC). Secondly, RED can accelerate the progress of largescale software development and course development due to its cost effectiveness, reusability, scalability and open source characteristics, thus bringing convenience to IT developers, tutors, course developers and learners. Company A in Singapore has made use of this benefit for generating more revenues. The Department of Engineering at the University of Cambridge (DEUC) has made use of this benefit for developing a student-centred model of learning. Thirdly, RED has further integrated with face-to-face training workshops, thus creating a greater improvement on both learning processes and learning efficiency as illustrated by the case study of DPUC.

However, there are two issues of awareness. Firstly, RED should not be over-used. If so, developers who over-deploy RED for many years may create a habit of over-relying on source codes. In addition, learners may suspect the accuracy of web resources due to an extremely high degree of information and resource overlapping. Secondly, it is difficult to trace those who have partially copied the resources: (a) the extent of resources being copied and (b) the extent of ideas being copied. These issues reveal that there are currently no definite guidelines for RED due to different policies and different practices in different organisations and in different countries. However, recommended practices and new standards should emerge due to the increasing implementation and awareness by growing numbers of organisations and practitioners.

\section{Key words}

Reusable e-learning development, reusable course materials, reusable e-learning resources.

\section{Topics and track}

Research/Education Methodology. Issues Related to IT, Research and Education. Systems, Applications and Tools.

\subsection{Introduction}

A reusable learning object (RLO) is a web-based multimedia digital resource based on a single learning objective, comprising a stand-alone collection of presentation, activity, assessment and links (Leeder et al, 2002, 2003). The advantage of RLOs is that they allow instructional designers to build small instructional components that can be re-used a number of times in different learning contexts (Wiley 2001). Reusable e-learning materials (REM) are e-learning or webbased resources generated from the combination of RLOs that utilise a wide range of multimedia components such as assessments and activities (Leeder et al, 2003).

Based on this concept, reusable e-learning development (RED) can be defined as a small-scale web development for REM, where a file or an image can be used repeatedly on all the web pages of a website. This concept is applicable to large-scale web development, which includes hundreds of files on a website or thousands of files between two or more different websites. In large scale-web development, RED can be defined as the cloning, modification and customisation of the existing files or source codes for developing another website or another web-based application. This is the definition and focus of this paper.

1.2 Reusable e-learning development: Case studies from the Department of Physics, University of Cambridge.

\subsubsection{Case Study 1: Redevelopment of the Cavendish Website}

Reusable e-learning development provides a practical technique for time-saving, improving efficiency and 
maximising utility of existing resources for creating another website or another web-based application. RED is particularly useful for large-scale web development in utilising and managing an extremely high degree of overlapping of information, resources and web designs. Therefore, RED has been widely adopted by growing number of knowledge-based organisations (KBO), including Information Technology and Higher Education. One example is the University of Cambridge, where numerous departments, including the Cavendish Laboratory, the home of the Department of Physics, have adopted RED as the web development strategy in the re-development of Cavendish website, which included:

(a) converting each existing ASP file into a standard HTML file, which follows HTML 4.0 with CSE HTML Validator as the web standard;

(b) transferring all the information on each existing ASP file to the standard HTML file;

(c) adding an university style sheet to each standard HTML file;

(d) retaining the same database structure between two different websites which include one containing approximately 600 ASP files and another one containing approximately 600 standard HTML files.

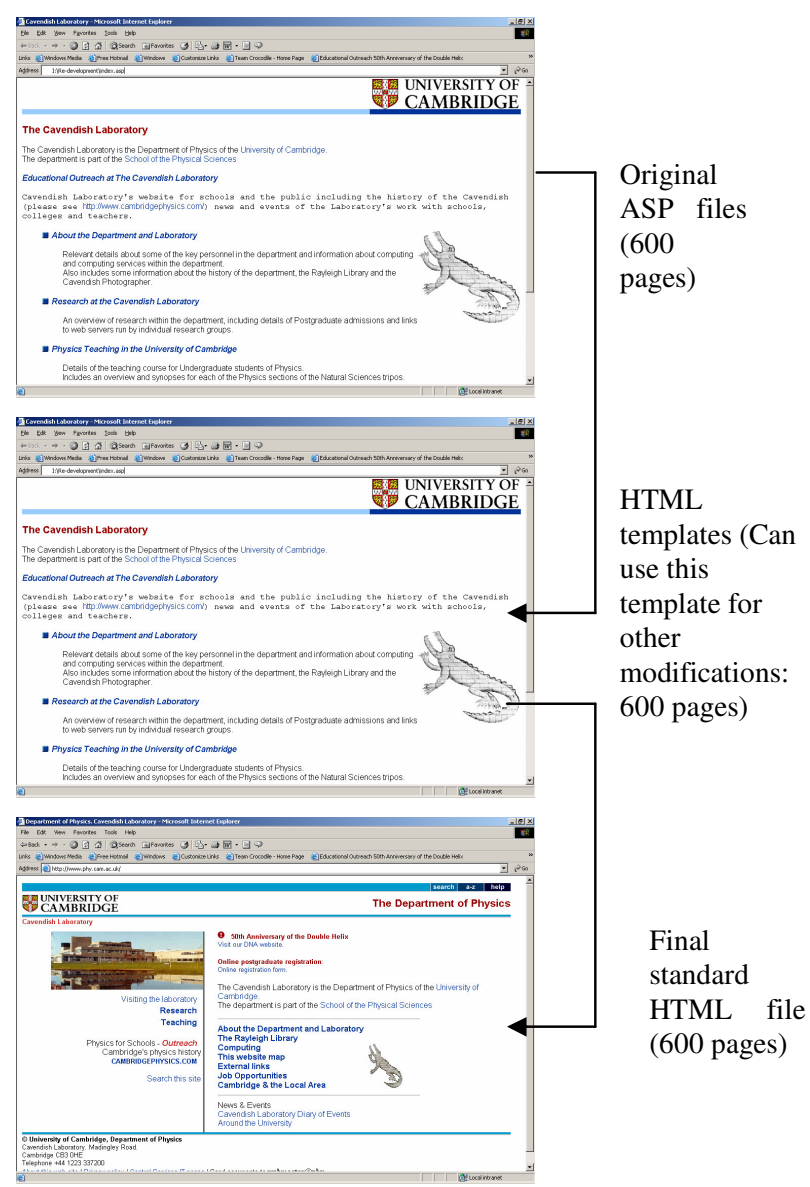

Figure 1: Re-development of Cavendish website

The estimated time for the re-development was 5 to 6 months due to the large number of webpages and modifications involved. However, the introduction of RED in 2003 has lead to an improved efficiency by minimising the completion time to 2 months in total. There is no secret for this, but the key factor is to design a working HTML template. Once this template is completed, it is saved as a different file, then transfer the information on the ASP file into this HTML template, and save this new HTML file as the same name as the ASP file. Then continue modification and debugging, until the ASP file is fully converted into a HTML file. In order to complete the whole process of re-development, it is essential to repeat this process 600 times and keep the modified files in another separate directory until the successful completion of web re-development. This strategy also applies to step two of the re-development, which includes adding an university style sheet on each page and following the University's policy in web designs and methods of navigation.

\subsubsection{Case Study 2: Cavendish Forum}

This is another technical example that adopts RED, which deploys PHP and MySQL. PHP has become increasingly popular and widely adopted by a growing number of organisations due to its open-source characteristics and strong performance in the integration with databases. The MySQL costs much less but performs nearly well compared with Oracle and that is why the combination of PHP-MySQL technology is chosen for the future generation of Cavendish website, particularly the Cavendish Forum. Between December 2002 and December 2003 the Department of Physics began development of an online Cavendish Forum based on PHP-MySQL technology. For the Cavendish Forum development of the source codes for PHP have been reused for modifications, customisations and testing until the successful implementation. The completion time for this RED was 1 year less than the estimated time of similar web development that would not have used any source codes.

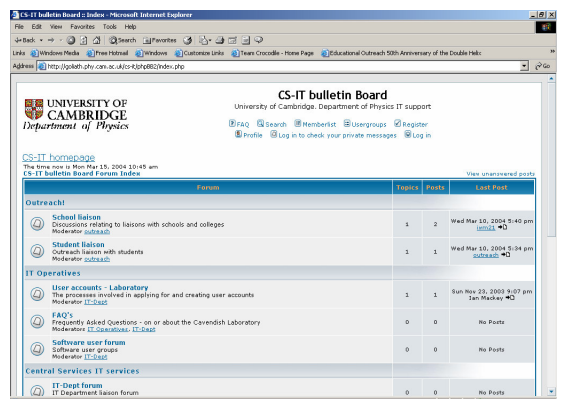

Figure 2: Cavendish Forum, another good example of showing the effectiveness of reusable e-learning development.

\subsubsection{Impacts on the web development and strategy of the Department of Physics when adopting RED}

Between September 1999 and September 2002, the majority of working time devoted to web development was spent researching different methods for creating an interactive webbased environment for the Department, including the Cavendish Diary, the Cavendish Forum and the redevelopment of the Cavendish website. There were issues about different ways of web development and it was difficult to reach a common agenda. However, the introduction and adoption of RED in October 2002 was a turning point: It had resulted in the successful implementation of the 
Cavendish Diary, the re-development of the Cavendish website and the Cavendish Forum in only 14 months. This illustrates the effectiveness of RED in the improvement in work efficiency by decreasing the quality project completion time: Before the introduction of RED 36 months of research did not yield any major developments; following the introduction of RED it took only 14 months to successfully implement 3 web-based projects.

\subsection{RED: Case study at the Department of Engineering, University of Cambridge}

Reusable e-learning development (RED) has been adopted at the Department of Engineering of the University of Cambridge, where an online system, "Online Management of Engineering Courses (OMEC)" was first proposed in October 2002. OMEC has integrated existing learning resources with web-based learning materials to create abundant e-learning resources for students and staff to learn new computing knowledge and to improve their programming skills, either through self-learning or directed-learning in the practical sessions. The major benefit of OMEC is that it does not restrict its functions to learning and course material presentation, but also incorporates marking and assessment to facilitate administration. Important functions include "module selection and module constraints", "supervision allocation and reporting", "examination entries", "examination results and class lists" and "user administration".

\subsection{Reusable e-learning development: Case study of Company $A$ in Singapore}

Reusable e-learning development (RED) has been widely practiced among software engineers and web developers, the majority of whom use source codes (software programs developed by software manufacturers or application service providers) as the main reference and modify these sources codes for developing web applications or developing other websites. This practice is extremely popular in the IT sector and more than $80 \%$ of software engineers and web developers adopt RED (Chang 2002, the role and effectiveness of elearning: key issues in an industrial context). A good example is Company A in Singapore, where the organisational name remains anonymous at their requests. Company $\mathrm{A}$ has employed nearly 200 web developers for creating and customising different web-based applications such as database-driven or e-commerce websites for their major clients. Company A pays annual licence fees of about $£ 50,000$ to get limited source codes from several global IT players, particularly Microsoft. Access to these source codes not only benefits web developers, who can make modifications and customisations with ease and reduce their average project completion time from 6 months to 2.5 months, but also benefits Company A, which has received clients' next contracts in advance and has also generated an estimate of $£ 180,000$ annual profit. The improvement of work efficiency and increment of annual revenues make several global companies, including Company A, believe reusable development, including RED, is a key factor in their successful IT management and strategic management.

\subsection{A demonstration on how reusable e-learning development can be done}

Reusable e-learning development (RED) is a common method for web development among developers, especially in the presence of source codes or working templates that have been developed previously. A working example is described here on how RED can be achieved.

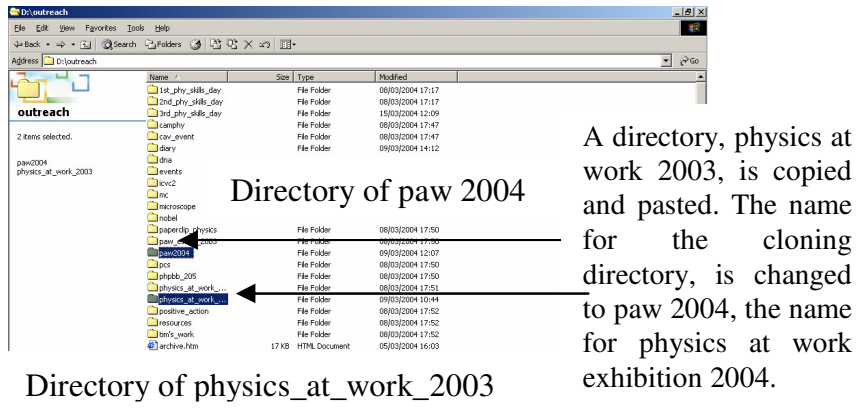

Figure 3: An example showing how RED can be achieved

The Directory for "physics at work 2003" contains all the information for annual exhibition in 2003. Due to the similarity between the 2003 and the 2004 event structure, and a high degree of information overlapping, RED is a key way for re-developing this website. Very little time is spent on designing layouts, exploring better methods of navigation and creating basic-level dynamic web pages that contain Javascript and CSS. The only major task is to change the hyperlinks and also the displayed information on each web page. The completion time for developing a website framework for our Physics at Work 2004 Exhibition event decreases from 10 working days (without using RED) to 1.5 days, which further supports the effectiveness of adopting RED.

\subsection{Reusable e-learning development for course development and content management}

In the context of education delivered by e-learning, a Virtual Learning Environment (VLE) is designed and adopted to facilitate learning processes and enhance learning efficiency. Among VLE, BlackBoard and WebCT are the most commonly used by the HE sector in the UK. There are several reasons for universities to move from class-based to webbased learning:

(1) providing flexible ways of learning for students due to the development of a student-centred learning model;

(2) increasing enrolments on and revenues from the benefit of distance learning programmes;

(3) improving the quality of education;

(4) convenience of reusing their course materials.

RED is also useful to course development and content management. In order to support this hypothesis, two case studies are presented and analysed in this section. 


\subsection{Another case study from the Department of Physics, University of Cambridge: Physics Skills Days}

At the Department of Physics, "Physics Skills Days" (PSD) form a series of events designed specifically for newly qualified teachers of physics, as well as those who do not have a background in physics. There have been three PSD so far since June 2003. On the second PSD last December, participants were asked to read online course materials on the existing Cambridge Physics website, where multimedia is used to explain some complicated concepts of Physics through simulations. The feedback from participants suggests that their knowledge of Physics has improved. This case study also implies that course materials can be re-used repeatedly each year, so that this saves time and effort for lecturers, who can repeat their lectures to different groups of students with the same learning materials by allocating these materials in the VLE. The reused course materials on Cambridge Physics website demonstrates a good example of how web-based course materials can be reused repeatedly and effectively with the combination of face-to-face workshops, eventually creating a greater effect on teaching and learning. The integration of e-learning and face-to-face learning is known as interactive learning (IL) and IL is reported to increase learning interests, enhance learning efficiency and improve learners' performance after their workshops (HP 2001; Katzy, 2000; Sloman, 2001, Chang 2002). In our case study, $90 \%$ of the feedback from 20 participating teachers consolidates these theories: the usefulness of the reused course materials and the effectiveness of IL.
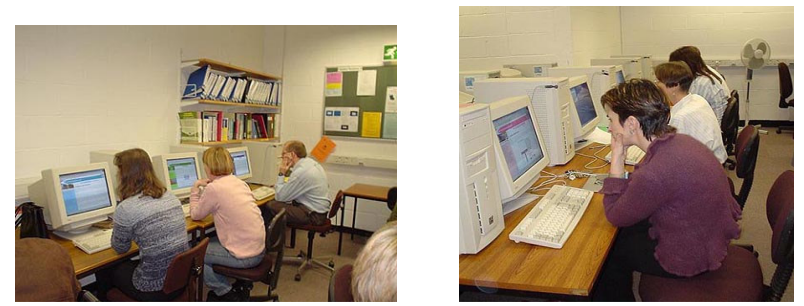

Figure 4 (a) and 4 (b): Participants improving their Physics skills by reading online course materials and multimedia simulations

\subsection{Another case study from the Institute for Manufacturing, Department of Engineering, University of Cambridge}

The Institute for Manufacturing (IFM) of the Department of Engineering has a Virtual Learning Environment (VLE) built on the BlackBoard technology that has been implemented by the Centre of Applied Research in Educational Technologies (CARET) that acts as a Cambridge software-outsourcing provider. When there are other Cambridge departments requesting CARET for developing their online curriculum in BlackBoard platform, there is a very high possibility of reusing the existing resources that are adaptable to BlackBoard, thus making reusable e-learning development (RED) likely to happen.

In the context of reusing course materials for teaching, VLE enables IFM academic staff to have the convenience of reusing their course materials. They can upload and save their course materials online safely, thus allowing them to reuse the same course materials repeatedly to different groups of undergraduate students each year. In order to validate the usefulness of this approach, interviews with 4 academic staff and 10 undergraduate students were conducted. Interviewing results suggest that $100 \%$ of academic staff enjoy the convenience of reusing course materials. This approach leads to a debate, as some researchers suggest that providing course materials online could make some students lazy, as they may not attend classes if they can easily obtain course materials. However, interviewing results also suggest that $90 \%$ of undergraduate students find that this way of learning has stimulated their interests and improved their learning efficiency. The students indicated that this is due to the easy ability to: (1) view the course materials and develop their thinking skills; (2) discuss various academic questions online; (3) receive new and useful ideas from peers; (4) receive answers from tutors in a shorter time and (5) develop the learner-centred model for learning.

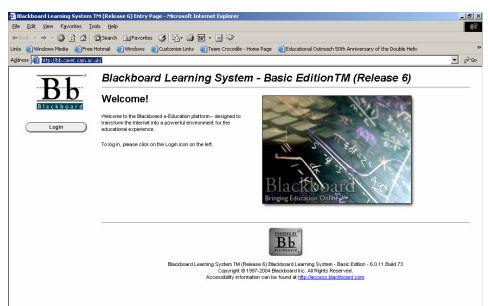

Figure 4: RED for learning and content management for the undergraduate students and academic staff of the Institute for Manufacturing, Cambridge.

\subsection{Issues of awareness for reusable e-learning development}

We have given various examples on how RED saves time and resources for web development, as well as increasing work efficiency in several cases. However, there are two major emerging issues about RED that have undesirable impacts on IT practices, which are summarised below.

\subsection{RED should not be over-used:}

We have illustrated the convenience in web development and course development benefited from RED, but misuses of this convenience may reverse the benefits that RED has brought, and we should be aware of the following traps. Firstly, developers who over-deploy RED for many years may create a habit of over-relying on source codes. Without source codes, those developers may find great difficulties in their programming work. Secondly, over-usage of RED will result in all the web-based resources having the same interfaces or designs, as well as having a high degree of similar information throughout the resources. This may bore some online visitors and learners, and some of them may suspect the accuracy of information displayed on the web due to the extremely high degree of repetition in information and interfaces.

There are a few recommended methods to offset these two undesirable issues. Firstly, the developers could create 4 
several sets of web designs and interfaces, with a different set used for each type of occasion, or each set used on a rotational basis. One example is the Cambridge Science Festival website, where a different set of web designs, interfaces and resources is deployed each year on rotation, and a small amount of information is reused each year. Secondly, the developers could add more varieties of resources and quick updates for the latest news. For instance, multimedia simulations, event announcements, photo galleries, articles written by different individuals and an online forum can be included on a website to make it more interactive and user-friendly. Once the learners and online visitors find different varieties of resources and information available and up-to-date, most of them have greater interest in returning to the site and discovering more about what they can learn from web-based resources.

\subsection{Issues about copyright and intellectual property}

There is always a growing number of websites and an increasing number of these websites stating their copyright authority to prevent illegal copying or downloading from the World Wide Web. It is not a difficult task to trace those who have completely copied web resources and made use of them for commercialisation or publication. However, it is a difficult task to identity those who have partially copied resources: (a) the extent of resources being copied, either in rephrasing the whole content or redevelopment of these resources without seeking the author's consent, and (b) the extent of the ideas of being copied, and later used to develop a completely different web interface and content for commercialisation or publication. There is currently no definite solution or guideline for improving this situation. One recommendation is to enforce a more stringent copyright law for web-based resources.

This also leads to the issue of Digital Rights Management (DRM), which poses one of the greatest challenges for content communities and information security in this digital age. The case of MP3 is an example of breaching copyright law due to the ease of downloading and transmitting music and digital files. Presently, DRM covers the description, identification, trading, protection, monitoring and tracking of all forms of rights usages over both tangible and intangible assets, including management of rights holders relationships. In the future generation of DRM, an advanced technology may be jointly implemented into the e-learning resources, focusing on e-learning content protection, aimed at protecting the sharable content objects and defining the range of what users can do or use. This will provide learners, tutors and organisations with safe digital environments, help to prevent plagiarisms and minimise digital crimes.

\subsection{Conclusion: Future for RED}

Due to its cost effectiveness, reusability, scalability and open source characteristics, RED saves developers time in creating web applications repetitively and also saves course developers from creating learning materials repetitively, thus improving work efficiency and convenience of reusable elearning resources for learners, tutors and developers. Therefore, there is growing interest and adoption of RED, which can be regarded as a constructive way for software engineering, web development and reusable course development.

However, issues of awareness involved in the use of RED should be strongly emphasised in order to minimise undesirable effects caused by over-using RED and the possibility of breaching copyright laws. In the context of elearning, there are guidelines such as:

- ADLN/SCORM - Advanced Distributed Learning Network/ Sharable Content Object Reference Model (US federal government)

- ARIADNE - Association of Remote Instructional Authoring and Distribution Networks for Europe (EC framework 3 programme)

- BSI IST/43 - British Standards Institute

- CEN/ISSS - Centre de European Normalisation / Information Society Standardisation System

- DCMI - Dublin Core Metadata Initiative

- IEEE LTSC - Institute of Electrical and Electronic Engineers, Learning Technology Standards Committee

- IMS Information Management Systems Global Learning Consortium

- $\quad$ ISO - International Standards Organisation

In this paper, RED is identified as an emerging area and useful method as illustrated by several case studies in Cambridge and Singapore. There are currently no definitive guidelines for RED and there are different policies and different practices in different organisations and in different countries. However, recommended practices and new standards should emerge in coming years due to the increasing implementation of RED by growing numbers of organisations and practitioners, and recent issues emerging from these implementations. Some of the best examples of guidelines for e-learning are listed above, the majority of which have taken less than 10 years to become validated.

\section{References}

1. Alexander S., "E-learning developments and experiences", Education + Training, Volume 43, No. 4/5, MCB University Press, 2001.

2. Chang V., 2003 "The role and effectiveness of e-learning: key issues in an industrial context", paper for the United Nations IS World Forum and 2002: "The role and effectiveness of e-learning", MPhil thesis.

3. Chang V., 2003 "Re-development of the Cavendish website", the report for Cavendish web strategy.

4. Chang V., 2004 "Stage 2 of the re-development of the Cavendish Website", the report for Cavendish web strategy.

5. Chang V., 2004 "Digital content protection and digital rights management architecture for the modern e-learning portal", the report for e-learning research. 
6. Grudin J., "Groupware: Eight challenges facing developers", Volume 31, Issue 1, Start Page 92, Jan 1994, ISSN: 00010782.

7. Hall M., 1998: “Core Web Programming”, Prentice Hall.

8. Hughs B, Cotterell M,1999: "Software Project Manaement", the $2^{\text {nd }}$ Edition, The McGraw-Hill Company, ISBN: 0077095057

9. Leeder, Wharrad, Davies 2002: "Beyond Institutional Boundaries: reusable learning objects for multi-professional education", Universities' Collaboration in eLearning (UCEL) Publication.

10. Leeder \& Wharrad, 2003: "Reusable Learning Objects for Health Professional Education", UCEL Publication.

11. Leeder \& Wharrad, 2003: "Experiences with Re-usable Learning Objects: Process and Evaluation", UCEL Publication.

12. Leeder, McLachlan, Rodrigues, Stephens, Wharrad, McElduff, 2003: 'Universities' Collaboration in eLearning (UCeL): a community of practice", UCEL Publication.

13. Leeder, McLachlan, Rodrigues, Stephens, Wharrad, McElduff, 2004: 'Universities' Collaboration in eLearning (UCeL): a virtual community of practice in health professional education", UCEL Publication.

14. Leeder \& Wharrad, 2004: "Reusable Learning Objects the easy way: how to make high quality eLearning content", UCEL Publication.

15. Muzio J., Heins T., Munndell R., 2002: "Experiences with Resuable eLearning Objects: From Theory to Practice".

16. Ritchie J., 2003: "e-Learning development at the University of Edinburgh".

17. Sloman M., "The e-learning revolution from propositions to action", Charted Institute of Personnel and Development, 2001, first edition.

18. Stiles, M.J., "Embedding eLearning in a Higher Education Institution", 12th - 13th September 2003, Mansfield College, Oxford.

19 Ullman L, 2001: "PHP for the World Wide Web", ISBN: 0-201-72787-0

20.Wiley, D. A 2001: "Connecting learning objects to instructional design theory: A definition, a metaphor, and a taxonomy." (http://reusability.org/read/chapters/wiley.doc)

Information from the web addresses of

- Department of Physics (Cavendish Laboratory), University of Cambridge: http://www.phy.cam.ac.uk

- Educational Outreach, Cavendish Laboratory: http://www-outreach.phy.cam.ac.uk

- Cambridge Physics http://www.phy.cam.ac.uk/camphy

- The Second Physics Skills Days: http://wwwoutreach.phy.cam.ac.uk/2nd_phy_skills_day

- Department of Engineering, University of Cambridge: http://www.eng.cam.ac.uk
- Institute for Manufacturing, Department of Engineering: http://www-mmd.eng.cam.ac.uk 